\title{
Differences in Measuring Market Risk in Four Subsectors of the Digital Economy
}

\author{
S. Benito, R. de Juan, R. Gómez and F. Mochón \\ Universidad Nacional de Educación a Distancia, ZED, Spain
}

\begin{abstract}
This paper defends the wisdom of not considering the Digital Economy to be one homogeneous sector. Our hypothesis is that it is best to consider it the result of adding four different subsectors. We test whether indeed the economic and financial performance of a portfolio of listed companies in each of the four subsectors presents relevant differences. We use the value at risk measure to estimate market risk of the four subsectors of the digital economy. The riskiest subsector is Mobile/Internet Contents \& Services followed by SW\&IT Services and Application Software. On the contrary, the Telecom sector is by far the safest one. These results support the hypothesis that the Digital Economy is not a homogeneous sector.
\end{abstract}

Keywords - digital economy, ICT, market risk, value at risk, volatility

\section{INTRODUCTION}

$\mathrm{D}$ ESPITE the importance of the Digital Economy, people often have two misconceptions when talking about it. The first mistake is to identify Digital Economy with ICT (Information and Communications Technology) sector. The second error is to consider the digital economy a homogeneous whole.

When the digital economy is identified with ICT, we are obviating that there is a big ecosystem of companies that provide digital content and services [1]. Moreover, the sector of the digital economy is not homogeneous. As we shall see in the next section, the Digital Economy covers various subsectors that have quite different characteristics.

In this regard, this article has two objectives: first, justify the different sectors that make up the digital economy from a technological and economic perspective; and second, find an objective criterion that allows us to verify the different nature of the subsectors mentioned.

To achieve these objectives, this paper has been structured as follows. In the next section, the various subsectors that make up the digital economy are analyzed. In the third section, a criterion is selected to evaluate the different behaviour of the various subsectors. The chosen criterion is market risk and volatility of financial returns. The fourth section presents the empirical analysis and the results are discussed. Finally, the fifth section presents the main conclusions.

\section{THE FOUR SUBSECTORS OF THE DIGITAL ECONOMY}

For most of the twentieth century, the telecommunications industry and the information technology industry were two distinct areas of activity. With the advent of the Internet, their paths crossed to the point of constituting a single industry known as ICT (Information and Communications Technology). In the context of ICT, all types of information (voice, data, and images) could already be processed, stored and transmitted between devices, at any time and from any location.

Additionally, in recent years, the explosion of mobile Internet, along with the phenomenon of smartphones, tablets and social networks, has promoted the creation of a new economic sector: the services and digital content sector. Thus, there are new companies able to offer thousands of new products and services to billions of users through all kinds of networked devices. It has created a true 'digital revolution' whose impact is much greater than any previous technological progress because of its transverse and disruptive nature.

This revolution not only changes the way we work and communicate, as was the case through the traditional ICT industry, but also creates new business models. These business models break the foundations on which the economic activities that have historically accounted for most of the world's GDP are based.

This whole phenomenon of convergence between traditional ICT companies and companies which provide services and digital content through all kinds of networks set an ecosystem that is commonly called the digital economy.

Companies participating in this digital economy are diverse and heterogeneous, occupying a very different place within the industry value chain. In practice, this means that we should speak necessarily of various subsectors within the Digital Economy. Thus, taking into account the position of firms in the value chain, four subsectors of homogeneous firms can be identified [2] (see Figure 1).

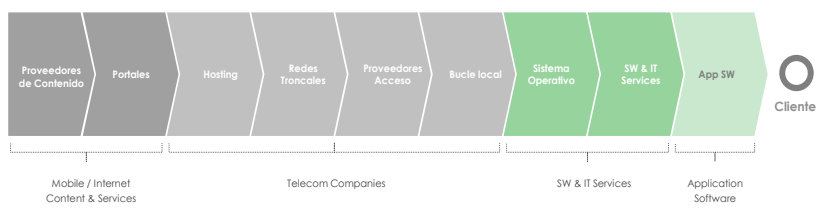

Fig. 1. The four subsectors of the digital economy 


\section{Telecommunications}

Companies in this subsector are responsible for ensuring connectivity and allowing content and online services to be delivered from content providers to physical devices with which customers can enjoy such contents.

These companies can perform many activities within the value chain: hosting, management backbones, Internet access supply and access to the local loop / client device, etc.

Increasingly, the role of telecommunications companies is becoming a 'commodity' and it is difficult to differentiate their products and services from those offered by their competitors.

In addition to the risk of 'commoditization,' we find other risks such as financial risks linked to high investments to be made every few years in network equipment, transmission and security; the appearance of new competitors and suppliers like cable TV and satellite operators; or OTT ${ }^{1}$ companies offering alternative services (e.g., WhatsApp, Skype, Waki, TV, Line, etc.) covered under the controversial principle of 'net neutrality.' There is also regulatory risk.

\section{Mobile/Internet Content and Services}

This subsector consists of companies that create or acquire content in various formats --text, audio, images, video, music, blogs, etc.-- and provide digital services that deliver value to their customers through the Internet (broadband networks and/or mobile), and can be enjoyed through many devices (PCs, smartphones, tablets, etc.).

In this subsector, two types of firms are grouped: i) companies that create and publish their own content, and ii) companies that add third-party content and publish it through a single Web/Wap portal. Also, these companies can distribute many types of content and services: news, entertainment, ecommerce, search engines, travel agencies, education, etc.

The main risks inherent to these companies deal with their innovativeness, ability to attract talent, rapid adaptation to changes in the habits and preferences of their users and the ability to monetize their products and services.

\section{Software and Information Technology (SW \& IT)} Services

Companies in this subsector develop SW and technology that allow users to enjoy online content and services offered through Internet-connected devices. The objective of these companies is to isolate the user from the technological complexity and provide a good user experience.

These companies are often subject to the so-called 'network effect' whereby users of a specific type of service benefit from the increase in the number of users who use it, which often leads to a few companies having a very high market share.

Other features of the market in which these companies operate and significantly affect their risk are product decisions concerning standardization against the 'customization' of the product, the high costs of change / replacement of the product, and being subject to the law of 'increasing returns', which means that the costs of creating the proprietary software are

\footnotetext{
${ }^{1}$ OTT, Over-The-Top, describes a scenario in which a telecommunications service provider delivers one or more of its services across all IPS.
}

very high while duplication or mass production costs are much smaller and are subject to strong economies of scale. This means that the marginal cost of producing an extra unit tends to zero as output increases.

\section{Application $S W$}

Such companies develop SW running on the Operating System (OS) of the device and help users to perform certain tasks, increasing their productivity.

This SW should be independent of specific hardware used and must be implemented without major problems in other devices and/or operating systems. It can also be distributed by building a 'bundle' with the operating system or be distributed independently.

The market in which the companies in this subsector operate also shares two characteristics of the previous subsector: the so-called 'network effect' and the law of 'increasing returns.'

Once we have submitted the four subsectors, we can formulate the following question: Is there any objective criterion that may ratify the existence of the four different subsectors?

From all the above, one might state that a different position of the companies from every subsector in the value chain of the digital economy would also imply a different degree of value added to the process and therefore a different risk for firms in each subsector.

Additionally, if the risk faced by enterprises is different within a subsector level, the target shareholder's return in each of the subsectors should also be. This fact (if true) should also be shown in the risk-return ratio inherent in the shares of listed companies in the digital economy.

To support this differentiation by subsectors, we will test whether indeed the economic and financial performance of a portfolio of listed companies in each of the four subsectors shows relevant differences.

More specifically, we will measure the financial risk of the four groups of companies representing the aforementioned subsectors. For this task, we will use two kinds of measures: (i) volatility, which is the traditional measure of risk, and (ii) Value at Risk, which is currently the most used.

\section{MEASURING MARKet Risk: Volatility - VAlUE AT RisK}

A context of risk is one in which we do not know with certainty the consequences associated with a decision. The only thing that we know is possible outcomes associated with it and the likelihood of achieving such results. In the financial

field, the notion of risk implies that we know the various yields can potentially get to make an investment??? and also know the probability of achieving such results. This allows us to estimate the average expected yield and the possible diversion 'above' or 'below' the average value, that is, the risk. The most popular and traditional risk measure is volatility (variance). In fact, traditional financial theory defines risk as the dispersion of returns due to movements in financial variables.

Another way of measuring risk, which is the most commonly used at present, is to evaluate the losses that may occur when 
the price of the asset that makes up the portfolio goes down. This is what Value at Risk (VaR) does. The Value at Risk of a portfolio indicates the maximum amount that an investor may lose over a given time horizon and with a given probability. In this case, the concept of risk is associated with the danger of losses. Since the Basel Committee on Bank Supervision at the Bank for International Settlements requires a financial institution to meet capital requirements on the basis of $\mathrm{VaR}$ estimates, this measurement has become a basic market risk management tool for financial institutions.

Formally, the Value at Risk of a portfolio at $(1-\alpha) \%$ confidence level is the $\alpha$ quantile of the probability distribution of the return portfolio. For instance, suppose that the Value at Risk of a bank's portfolio on the horizon of 1 day is $-3.5 \%$ with a confidence level of $95 \%$. This means that with a probability of $95 \%$, the return of the portfolio will be higher than $-3.5 \%$. There is still a $5 \%$ chance that the return of the portfolio will be below $-3.5 \%$.

Although the concept of Value at Risk is very simple to calculate, it brings some difficulties. ${ }^{2}$ Under the framework of the parametric techniques, the estimation of the Value at Risk requires a forecast of the portfolio return's conditional volatility.

The volatility of the financial returns can be estimated using different models. In this paper, we use the beta-skewness-tEGARCH model proposed recently by Harvey and Sucarrant (2013). This model captures some of the characteristics of the financial returns like (i) 'cluster in volatility' and (ii) the 'leverage effect'. The former means that large returns in absolute value are likely followed by other large returns in absolute value, and small returns in absolute value are followed by small returns in absolute value. The leverage effect means that volatility tends to be higher after negative returns; this is typically attributed to leverage (hence the name). For the estimation of the volatility model, we assume that the probability of the return portfolio going below zero (daily average return) is higher than the probability of going above zero, which is in keeping with the empirical evidence (skewness distribution).

To evaluate the accuracy of these estimations, we- will use several standard tests (see Appendix A). In addition, we use Lopez's loss function to measure the magnitude of the no cover losses. The losses are not covered when the portfolio return goes below VaR. For instance, at time $t$, the value at risk of a portfolio 1 day ahead is $-3.5 \%$. A day later, we observe that the return portfolio was $-5.0 \%$. In this case, $1.5 \%$ of the losses were not covered.

In the following sections, we use the value at risk measure to estimate market risk of the four subsectors of the digital economy: (i) Telecom Companies; (ii) Mobile/Internet Contents and Services; (iii) SW\&IT Services and (iv)

\footnotetext{
${ }^{2}$ To estimate the Value at Risk of a portfolio, several methodologies have been developed: (i) the parametric approach; (ii) the non-parametric approach and (iii) the semi-parametric method. The parametric approach is the one most used by financial institutions. In Appendix A, we describe carefully how to calculate VaR using this methodology and summarize the backtesting procedure used to evaluate the VaR estimate.
}

Application Software. According to the Value at Risk estimates, we find important differences between markets.

\section{EMPIRICAL APPLICATION}

\section{A. Data Analysis}

The data used are the closing prices of daily stock quotes obtained from Yahoo Finance. The two stock indexes where they have been quoted are in NasdaqGS and in the NYSE, with the exception of the Samsung C \& T Corporation, which is traded only in Korea. The reference period is January 3, 2000 to July 15,2014 . The sample used consists of 29 firms. ${ }^{3}$ These companies have been classified into four homogeneous subsectors: Telecom, Mobile/Internet Contents \& Services, SW\&IT Services and Application Software. The four subsectors comprise the following companies: Telecom is composed of AT\&T, BT, Orange, Telefónica, Verizon, Vodafone, Vimpelcom and Shaw Communications. Mobile/Internet Contents \& Services consists of Amazon, Apple, Ebay, Priceline, Yahoo and Netflix. SW\&IT Services contains Microsoft, Oracle, IBM, Citrix, Ca Technologies, Adobe and SAP. Application Software consists of ADP, Autodesk, Cerner, Cognizant, Fiserv, Intuit and Symantec.

Given the high number of companies that integrate the different subsectors, it is helpful to elaborate indexes that allow us to aggregate the information and facilitate the analysis. In this regard, we define a representative portfolio per subsector

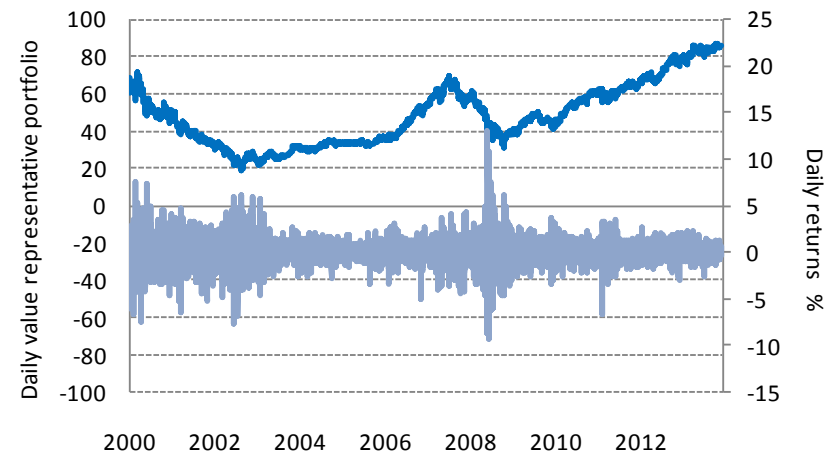

Fig. 2. Telecom

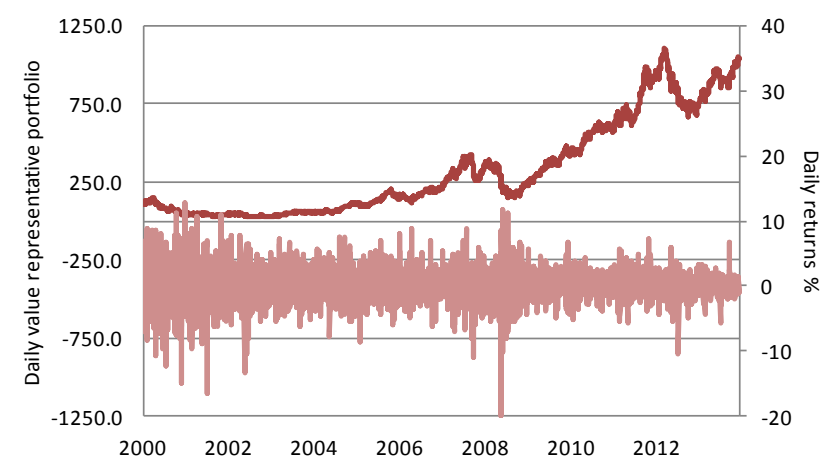

Fig. 3. Mobile/Internet

\footnotetext{
${ }^{3}$ The initial sample consists of 40 companies within the digital economy and the service sector. However, we have eliminated 12 firms because they are young companies listed on the stock exchange after January 3, 2000.
} 


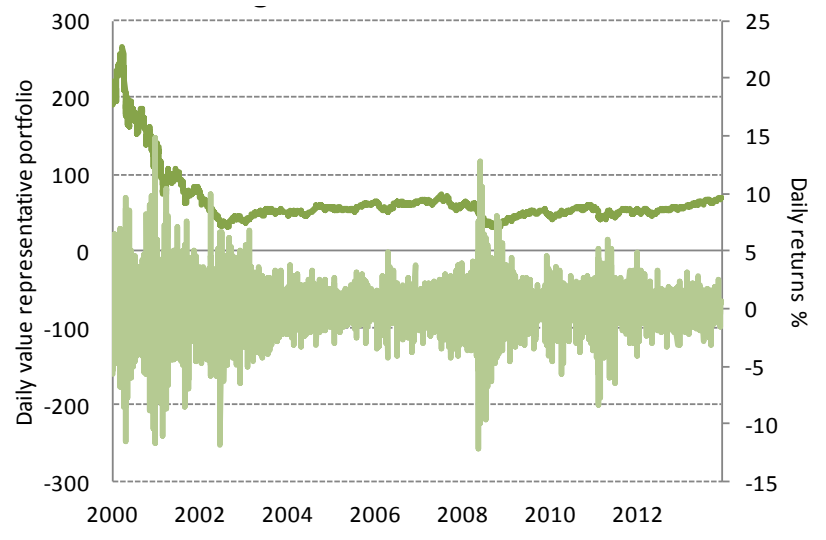

Fig. 4. SW\&IT Services

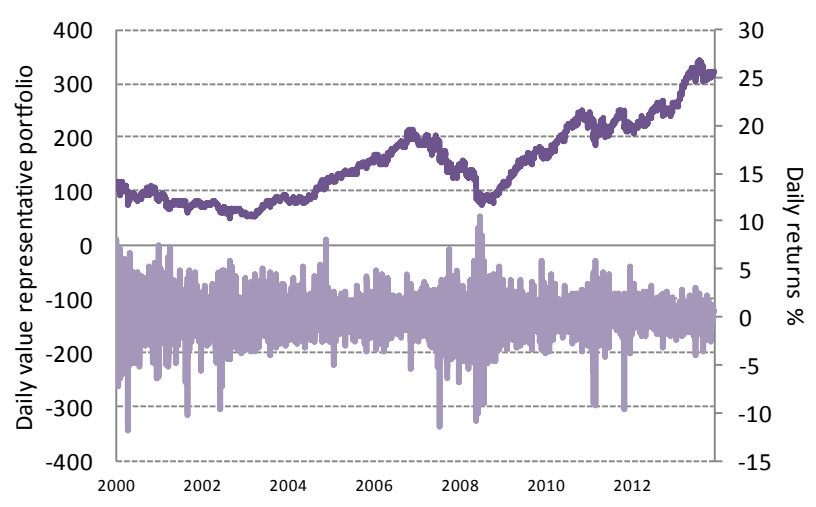

Fig. 5. Application Software

The evolution of the daily value of the portfolio of $S W \& I T$ Services shows a strong decline from late 2000 to mid-2003. In the remaining period, there were slight variations in the portfolio value. In this subsector, we observed a moderate profile that is typical of a mature market, even a technologically advanced sector. This is indicative of the rate of advances occurring in the field of Digital Economy. In the evolution of the daily value of the Telecom portfolio, the range of fluctuation is very small (between 19.3 and 86.9), so the prices are quite stable in this portfolio. The effect of the international financial crisis is hardly felt.

Table 1 contains descriptive statistics of the returns per portfolio. For each portfolio, the unconditional mean of daily return is very close to zero (for example, Telecom (0.01)).

$$
\text { TABLE I }
$$

DESCRIPTIVE STATISTICS OF DAILY RETURNS SERIES

\begin{tabular}{lcccc} 
& Telecom & $\begin{array}{c}\text { Mobile / } \\
\text { Internet }\end{array}$ & $\begin{array}{c}\text { SW\&IT } \\
\text { Services }\end{array}$ & $\begin{array}{c}\text { Application } \\
\text { Software }\end{array}$ \\
\hline Mean & 0.01 & 0.06 & -0.03 & 0.03 \\
Std. Deviation & 1.5 & 2.51 & 2.14 & 1.89 \\
Skewness & -0.02 & $-0.34 * *$ & $-0.16^{* *}$ & $-0.37 * *$ \\
Kurtosis & $5.92 * *$ & $4.16^{* *}$ & $4.66^{* *}$ & $4.03 * *$ \\
Minimum & -9.26 & -20.04 & -12.09 & -11.97 \\
Maximum & 13.11 & 14.84 & 14.84 & 10.5 \\
\hline Note: **
\end{tabular}

Note: $* *$ denotes significant statistics at $1 \%$ level.
It means that the fluctuations of positive and negative daily returns of each portfolio tend on average to offset. The unconditional standard deviation is especially high for Mobile/Internet Contents \& Services (2.51), followed by SW\&IT Services (2.14) and Application Software (1.89). Therefore, the daily returns on these portfolios vary considerably from day to day. In the first two aforementioned subsectors, their portfolios underwent great changes in the daily returns over the period considered. Far from these estimations, we find the Telecom subsector with a standard deviation of (1.5). These results indicate that according to the traditional measure of risk, the most traditional subsector in the digital economy is the safest. Furthermore, these results show that the Telecom market is a mature sector with few prospects for growth. On the contrary, the Mobile/Internet Contents \& Services sector is the riskiest, typical of a young, dynamic and growing sector.

The skewness statistic is negative in all the portfolios, especially with a more negative value in Mobile/Internet Contents \& Services (-0.34) and Application Software (-0.37). Thus, the distribution of those returns is skewed to the left. This means that the probability that the daily return is negative is greater than the probability that the daily return is positive. The excess kurtosis is very large and significant at $1 \%$ level, implying that the distributions of those returns have much thicker tails than the normal distribution. These results are in line with those obtained by Bollerslev [3], Bali and Theodossiou [4], and Bali et al. [5], among others. All of them find evidence that the empirical distribution of the financial return exhibits a significant excess of kurtosis (fat tails and peakness). This descriptive analysis reveals that Mobile/Internet Contents \& Services is the most asymmetric, plus one of the most volatile subsectors.

\section{B. The Value at Risk of the portfolio representative}

In this section, we calculate the Value at Risk of a portfolio representative of each subsector. The VaR has been calculated at one day ahead at $1 \%$ probability. The data period is divided into a learning sample from January 3, 2000 to December 31, 2007 and a forecast sample from January 1, 2008 to the end of June 2014.

In Figures 6 to 8, we present the daily VaR estimates for each representative portfolio, hereinafter expected losses. After the fall of the Lehman Brothers; in September 2008, the expected losses increased considerably in all markets, reaching double figures. This increase must be contextualized in a context of global financial and economic crisis which continued until the end of 2009. In 2010, expected losses returned to pre-crisis levels. Two years later, expected losses again soared, although this time with less intensity than in 2008. Although in qualitative terms the expected losses have a similar behaviour in all markets, in quantitative terms there are significant differences between them.

In Figure 8, we present the average of the daily Value at Risk estimate, i.e., the average of the expected losses for each portfolio.

During the analyzed period, the highest expected losses are observed in the Mobile/Internet Contents \& Services (-5.3\%) 
market subsector, while in the Telecom $(-3.1 \%)$ sector, the expected losses are the lowest. ${ }^{4}$ These percentages mean that, for instance, for a portfolio value of 500,000 euros, the expected losses would be 26,500 euros in the Mobile/Internet Contents \& Services sector and 15,500 euros in the Telecom sector.

Thus, the risk of investment in Mobile/Internet Contents \& Services companies is higher than Telecom companies.

However, we have not observed significant differences between SW\&IT Services and Application Software.

As higher risk implies higher yield, these results are coherent with the fact that the yield of Mobile/Internet Contents \& Services companies has been the highest. These companies are the big winners in the digital economy, creating more profitable but riskier investments.

Once we have estimated the Value at Risk per subsector, we proceed to evaluate the accuracy of the VaR estimates and calculate the average of the unexpected losses.

Table 2 shows the percentage of exceptions for the 4 subsectors. These percentages are marked in bold. Below the percentages, we present the statistics used to test the accuracy of the VaR estimates. These statistics are as follows: (i) the unconditional coverage test (LRuc); (ii) statistics for serial independence (LRind); (iii) the conditional coverage test (LRcc) and (iv) the dynamic quantile test (DQ). In all subsectors, the percentage of exceptions is very close to the theoretical level, which is $1 \%$, so it seems that the VaR estimates are accurate in all markets. This result is corroborated by the statistical test.

Table 3 displays the average of the no cover losses which are measured by López's loss function (see Appendix A). In a comparison between subsectors, we observe that the no cover losses are lower in the Telecom sector and SW\&IT Services sector, which are the most traditional markets among the digital global market. By contrast, in the Mobile/Internet Contents \& Services market, the no cover losses are the highest, followed by the Application Software subsector. ${ }^{5}$

To this point, we can conclude that whatever measure we use to evaluate risk, variance and/or value at risk, we find important differences between the four subsectors of the digital economy. In particular, we find that the riskiest sector is Mobile/Internet Contents \& Services. In contrast, the Telecom sector is by far the safest one.

\footnotetext{
${ }^{4}$ To assert the robustness of the result, we have calculated VaR using other volatility models like the standard GARCH [6] and the beta-t-EGARCH model proposed by Harvey and Chakravarty [7]. All of them provide the same results.

${ }^{5}$ Again we find that this result is robust to the volatility model used to forecast VaR, being the standard GARCH [6] and the beta-t-EGARCH model the two alternative models we have considered. These models have been estimated below a symmetric distribution (student-t).

Furthermore, in a comparison between models for each subsector, we find that the Beta-skewness-t-EGARCH model provides by far the lowest no cover losses. From this analysis, we can conclude that the fat-tailed and skewness distributions for conditional volatility outperform symmetric distribution in forecasting VaR. This result is in line with those presented by $\mathrm{Xu}$ and Wirjanto [8], Polanski and Stoja [9] and Chen et al. [10].
}

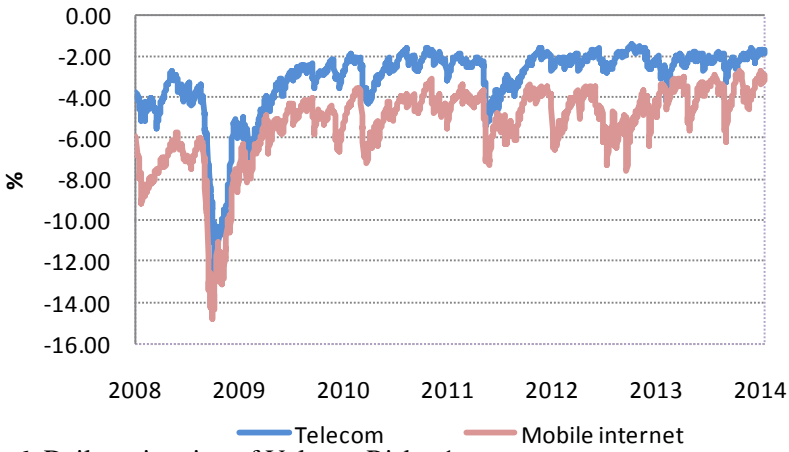

Fig. 6. Daily estimation of Value at Risk - 1

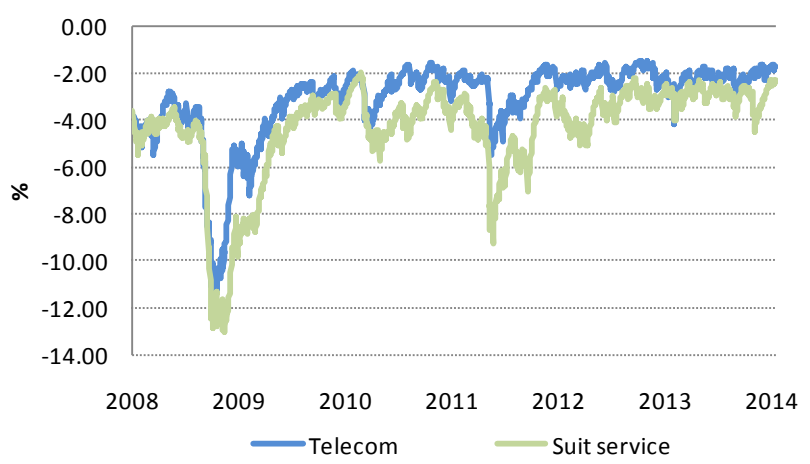

Fig. 7. Daily estimation of Value at Risk - 2

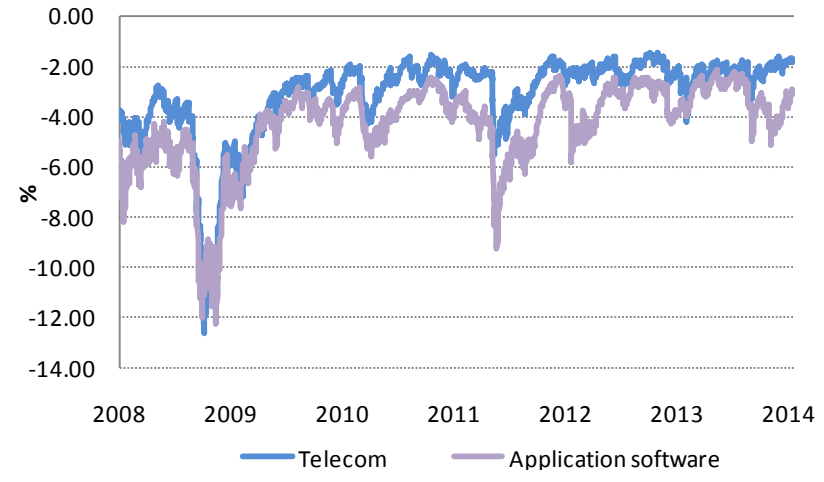

Fig. 8. Daily estimation of Value at Risk - 3

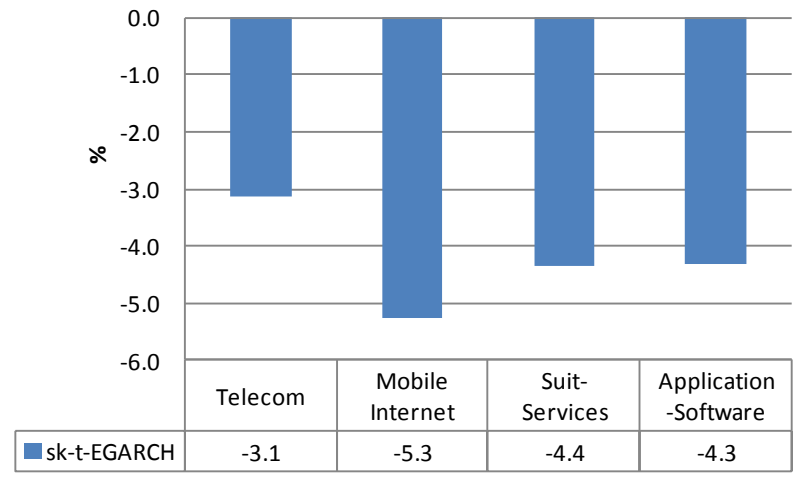

Fig. 9. Average of the daily VaR estimates 
TABLE II

THE ACCURACY OF VAR ESTIMATES

\begin{tabular}{lcccc} 
& Telecom & $\begin{array}{c}\text { Mobile / } \\
\text { Internet }\end{array}$ & $\begin{array}{c}\text { SW\&IT } \\
\text { Services }\end{array}$ & $\begin{array}{c}\text { Application } \\
\text { Software }\end{array}$ \\
\hline LR $_{\mathrm{UC}}$ & $\mathbf{1 . 1 0}$ & $\mathbf{0 . 8 6}$ & $\mathbf{1 . 2 2}$ & $\mathbf{1 . 1 6}$ \\
$\mathrm{LR}_{\mathrm{IND}}$ & 0.10 & 0.14 & 0.63 & 0.04 \\
LRcc & 0.17 & 0.10 & 0.23 & 0.11 \\
$\mathrm{DQ}$ & 0.27 & 0.23 & 0.86 & 0.15 \\
\hline
\end{tabular}

Note: LRuc denotes the unconditional coverage test; LRcc denotes the conditional coverage test; LRind: denotes the independence test; DQ denotes the Dynamic Quantile test. * indicates that the null hypothesis is rejected at $5 \%$ level.

TABLE III

MAGNITUDE OF THE LOSS FUNCTION

Telecom Mobile / SW\&IT Applicatio Internet Services n Software

Average of the loss function

0.02

0.1

0.04

0.05

Note: Bold figures denote the minimum value of the loss function.

\section{V.CONCLUSION}

The digital economy sector is not a homogeneous sector. Four distinct subsectors are observed: Telecom Companies; Mobile/Internet Contents and Services; SW\&IT Services and Application Software.

The nature of the business models of these subsectors is different, each one presenting very different risk profiles.

According to the traditional measure of risk, which is variance, the riskiest subsector is Mobile/Internet Contents \& Services, followed by SW\&IT Services and Application Software. In contrast, the Telecom sector is by far the safest one.

Measuring risk through value at risk methodology, which is the most commonly used at present, the results are qualitatively similar. According to this methodology, the highest expected losses are observed in the Mobile/Internet content \& Services subsector, while in the Telecom sector, the expected losses are the lowest. That implies that the risk of investment in Mobile/Internet Contents\&Services companies is higher than in Telecom companies.

As higher risk implies higher yield, these results are coherent with the fact that the yield of Mobile/Internet Contents \& Services companies is the highest in the digital economy market.

In addition, we find that no cover losses are lower in the Telecom sector and the SW\&IT Services sector, which are the most traditional markets among the digital global market. In contrast, in the Mobile/Internet Contents \& Services market, the no cover losses are the highest, followed by the Application Software subsector.
APPENDIX A. VALUE AT RisK METHODOLOGY

In this appendix, we present the concept of Value at Risk (VaR) and how to calculate it. In addition, we summarize the backtesting procedure we have used to evaluate the VaR estimates.

According to Jorion [11], the VaR measure is defined as the worst expected loss over a given horizon under normal market conditions at a given level of confidence. The VaR is thus a conditional quantile of the distribution of asset returns. Use $\mathrm{F}(r)$ to denote the cumulative distribution function, $F(r)=\operatorname{Pr}\left(r_{\mathrm{t}}<r f^{\Omega_{\mathrm{t}-1}}\right)$, conditionally on the information set ' $\Omega_{\mathrm{t}-1}$ that is available at time $t-1$. The $\mathrm{VaR}$ with a given probability $\alpha \in(0.1)$ denoted by $\operatorname{VaR}(\alpha)$ is defined as the quantile of the probability distribution of financial returns: $\mathrm{F}(\operatorname{VaR}(\alpha))=\operatorname{Pr}\left(r_{\mathrm{t}}<\operatorname{VaR}(\alpha)\right)=\alpha$

Under the framework of the parametric techniques [11], the conditional $\mathrm{VaR}$ can be calculated as $\operatorname{VaR}_{\mathrm{t}+1}(\alpha)=\mu_{\mathrm{t}+1}+\sigma_{\mathrm{t}+1} * \mathrm{k} \alpha$, where $\mu_{\mathrm{t}+1}$ represents the conditional mean, which we assume is zero, $\sigma_{t+1}$ is the conditional standard deviation and $k \alpha$ denotes the corresponding quantile of the distribution of the standardized returns at a given confidence level 1- $\alpha$. For instance, if we assume a normal distribution for the financial returns, $k \alpha$ will be the quantile of the standardized normal distribution.

In this paper, we forecast value at risk one day ahead at $1 \%$ probability. To forecast the conditional standard deviation of the return portfolio which is required for the $\mathrm{VaR}$ estimate, we use the Beta-skewness-t-EGARCH model proposed by Harvey and Sucarrant [12]. This model has been estimated below an asymmetric student-t distribution.

To test the accuracy of the VaR estimate, we use several standard tests: unconditional coverage tests, conditional coverage tests, the Back-Testing criterion and the Dynamic Quantile test.

We have an exception when $r_{t+1}<\operatorname{VaR}_{t+1}(\alpha)$; in this case, the exception indicator variable $\left(\mathrm{I}_{\mathrm{t}+1}\right)$ is equal to one (zero in other cases). Kupiec [13] shows that the unconditional coverage test has as a null hypothesis, with a likelihood ratio statistic given by

$$
L R_{U C}=2\left[\log \left(\widehat{\alpha}^{x}(1-\widehat{\alpha})^{N-x}\right)-\log \left(\alpha^{x}(1-\alpha)^{N-x}\right)\right]
$$

which follows an asymptotic $\chi^{2}(1)$ distribution. The conditional coverage test [14] jointly examines whether the percentage of exceptions is statistically equal to the expected percentage and the serial independence of $\mathrm{I}_{\mathrm{t}+1}$. The likelihood ratio statistic of the conditional coverage test is LRcc=LRuc+LRind, which is asymptotically distributed $\chi^{2}(1)$, and the LRind statistic is the likelihood ratio statistic for the hypothesis of serial independence against first-order Markov dependence. Finally, the dynamic quantile test proposed by Engle and Manganelli [15] examines whether the exception indicator is uncorrelated with any variable that belongs to the information set ' $\Omega_{\mathrm{t}-1}$ available when the VaR was calculated. This is a Wald test of the hypothesis that all slopes are zero in a regression of the exception indicator variable on a constant, five lags and the $\mathrm{VaR}$. 
Additionally, we evaluate the magnitude of the losses experienced. For this purpose, we have considered the loss function proposed by Lopez [16],[17]. This function reflects the utility function of a regulator. This loss function assigns a quadratic specification when the observed portfolio losses exceed the VaR estimate. Thus, we penalize only when an exception occurs according to the following quadratic specification:

$$
R L F_{t}=\left\{\begin{array}{lr}
\left(\operatorname{VaR}_{t}-r_{t}\right)^{2} & \text { if } \quad r_{t}<\text { VaR } \\
0 & \text { otherwise }
\end{array}\right.
$$

This loss function gives higher scores when failures take place and considers the magnitude of these failures. In addition, the quadratic term ensures that large failures are penalized more than small failures.

APPENDIX B. THE METHOD OF PRINCIPAL COMPONENTS

$$
\text { ANALYSIS }
$$

We use the method of Principal Components Analysis (PCA) to calculate linear indexes constructed using the closing daily prices per firms. PCA is a statistical procedure used to reduce the dimensionality of a data set. Intuitively, the technique finds the causes of variability in a data set and sorts them by importance. PCA uses an orthogonal transformation to convert a set of observations of possibly correlated variables into a set of values of linearly uncorrelated variables called principal components. This transformation is defined in such a way that the first principal component has the largest possible variance (that is, accounts for as much of the variability in the data as possible), and each succeeding component in turn has the highest variance possible under the constraint that it is orthogonal to (i.e., uncorrelated with) the preceding components. The first principal component is used to derive the weights of the index. Figure A1 summarizes the first principal component per subsector. Each graph shows the weight that each firm has in the composition of the first principal component per subsector. Therefore, the first component can be interpreted as a representative portfolio per subsector. In each subsector, the total explained variable is over $50 \%$, with the exception of the Mobile/Internet sector $(46 \%)$.

Telecom

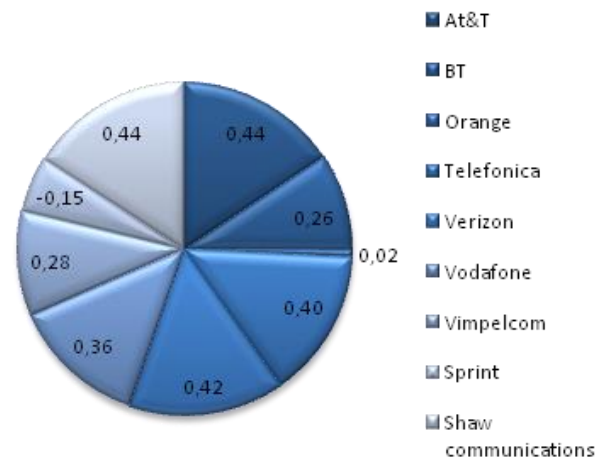

Mobile / Internet Contents \& Services

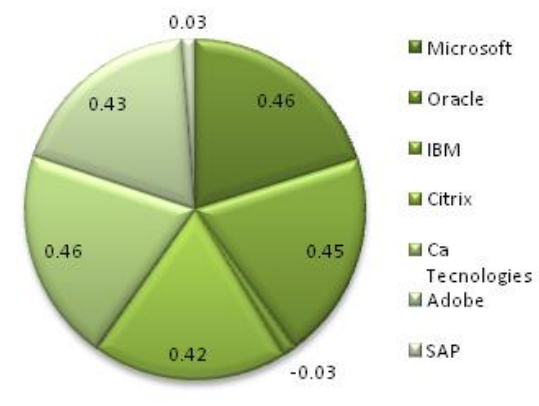

Application Software

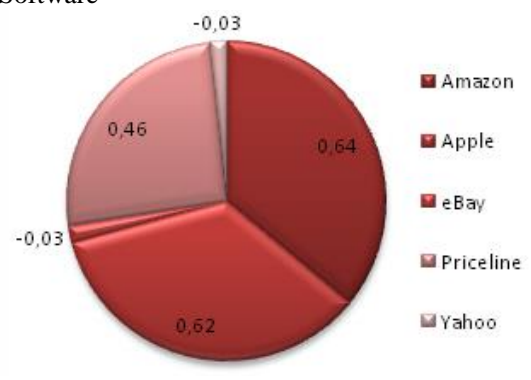

SW\&IT Services

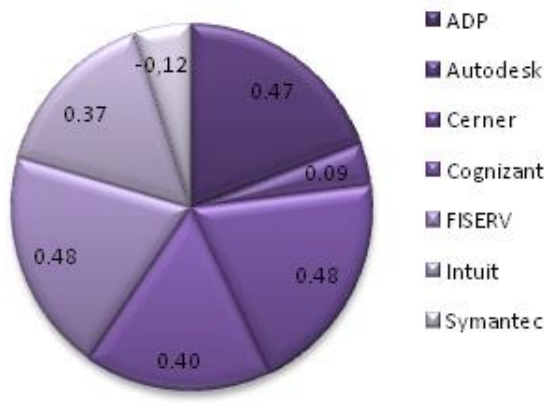

Fig. 10. The first principal component per subsector

\section{REFERENCES}

[1] J. Calderón, "La historia de un mundo digital," in Economía digital. Curso MOOC. F. Mochón, J. C. Gonzálvez and J. Calderón. Alfaomega, 2014.

[2] Goldman Sachs. Publications by Sector/Industry https://360.gs.com/gs/portal/research/industrylist.

[3] Bollerslev, "A Conditionally heteroskedastic time series model for speculative prices and rates of return." Review of Economics and Statistics, vol. 69, pp. 542-547, 1987.

[4] T. Bali and P. Theodossiou, "A conditional-SGT-VaR approach with alternative GARCH models," Annals of Operations Research, vol. 151, pp. 241-267, 2007.

[5] T. Bali, M. Hengyong and Y. Tang, "The role of autoregressive conditional skewness and kurtosis in the estimation of conditional VaR." Journal of Banking \& Finance vol. 32(2), pp. 269-282, 2008.

[6] T. Bollerslev, "Generalized Autoregressive Conditional Heteroscedasticity." Journal of Econometrics, vol. 21, pp. 307-327, 1986.

[7] A.C. Harvey and T. Chakravarty, Cambridge Working paper in Economics, CWPE 0840, 2008.

[8] D. Xu, T. Wirjanto, "An empirical characteristic function approach to VaR under a mixture-of-normal distribution." The Journal of Derivatives, vol. 18(1), pp. 39-58, 2010.

[9] A. Polanski and E. Stoja, "Incorporating higher moments into Value-atRisk forecasting." Journal of Forecasting, vol. 29(6), pp. 523-535, 2010. 
[10] C. Chen, R. Gerlach, E. Lin and W. Lee, "Bayesian forecasting for financial risk management, pre and post the global financial crisis." Journal of Forecasting, vol. 31(8), pp. 661-687, 2012.

[11] P. Jorion, Value at Risk: The New Benchmark for Managing Financial Risk. McGraw-Hill, 2001.

[12] A. Harvey and G. Sucarrant, "EGARCH models with fat tail, skewness and leverage." Computational Statistics and Data Analysis, vol. 76, pp. 320-338, 2014.

[13] P. Kupiec, "Techniques for Verifying the Accuracy of Risk Measurement Models." Journal of Derivatives, vol. 2, pp. 73-84, 1995.

[14] P. Christoffersen, "Evaluating interval forecasting." International Economic Review, vol. 39, pp. 841-862, 1998.

[15] R. Engle and S. Manganelli, "CAViaR: Conditional Autoregressive Value at Risk by Regression Quantiles." Journal of Business \& Economic Statistics, vol. 22 (4), pp. 367-381, 2004.

[16] J.A. Lopez, "Testing your Risk Tests." Financial Survey, pp. 18-20, May-June 1998.

[17] J.A. Lopez, "Methods for Evaluating Value-at-Risk Estimates." Economic Review Federal Reserve Bank of San Francisco, vol. 2, pp. $3-17,1999$.

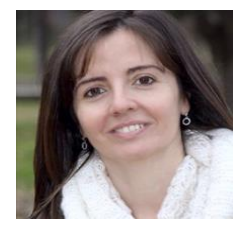

Sonia Benito Professor, Department of Economics, UNED, (Spain). Ph.D. in Economics from the Universidad Complutense (Spain). She has pursued her research in Empirical Finance: interest rate common factors, financial returns volatility and finance risk management (Value at Risk). She is the author of several articles, published both in Spanish and international magazines, particularly in the field of finance. She also took part in five projects (CICYT) funded by the Spanish Ministry of Education between 2003 and 2015. She has participated in more than 15 national and international congresses, conferences and seminars, mainly as a speaker.

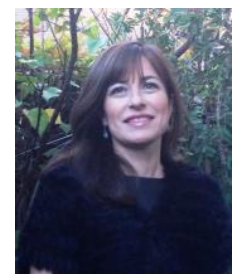

Rebeca de Juan, Professor, Department of Economics, UNED (Spain). Ph.D. in Economics from the UNED (Spain) and Master in Economic Analysis and Public Finance from the Instituto de Estudios Fiscales. She has been a researcher in the Program for Economic Research at the Fundación Empresa Pública (19942002). The research is focused on industrial organization, the banking sector, happiness and digital economy. This research has led to participation in various projects (CICYT) and in private research projects. She has received several special awards. She has published several articles and books.

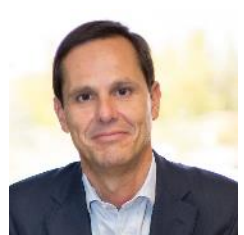

Ricardo Gómez. Holds an MSc in Industrial Engineering at Universidad Politecnica de Madrid and an MBA from IESE Business School. Currently is Chief Operations Officer at Zed Group where he has formerly held several positions: Organization\&Project Director and Corporate Development Director. Prior to joining Zed, held several finance and management positions at Grupo Ferrovial, Cintra and Accenture.

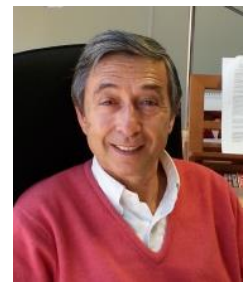

Francisco Mochón. $\mathrm{PhD}$ in economics from Indiana University and the Autonomous University of Madrid. Currently is full Professor of Economic Analysis at the UNED. He has been Advisor to the Ministry of Economy and Finance of Spain, and Chief Financial Officer (CFO) of Telefónica of Spain. Currently is a member of the advisory committee of the Futures Market of Olive Oil (MFAO). He has published numerous research articles and is the author of more than fifty books on economics, finance and business. Currently his research interest is the Digital Economy. 